\title{
León Florido, Francisco y Rodamilans Ramos, Fernando. El problema de la resurrección y la vida futura en el siglo XIV. Madrid: Sindéresis, 2016.
}

Este texto presenta de manera temática o problémica algunas preguntas de orden escatológico, esencialmente sobre la resurrección y la vida futura, en el contexto propio de la tradición cristiana y la teología católica. Partiendo de una sintética exposición general y, posteriormente, con la ayuda de textos seleccionados, los autores retoman el interrogante sobre la resurrección general en el futuro, continuando con la pregunta por la resurrección del ser humano en cuerpo y alma, y terminando con el seguimiento a la pregunta por la visión beatífica, entendida como recompensa en el cielo.

La particularidad se configura en la manera como se presentan textos seleccionados de algunos teólogos del siglo xIv: Gonzalo Hispano, Juan Duns Escoto, Guillermo De Ockham y Roberto Holcot, que dan cuenta de las polémicas teológicas del siglo XIV. Estos, seguramente, podrán ser considerados como material de estudio en la enseñanza de la historia de la iglesia, así como de tratados fundamentales de la teología como Misterio de Dios Uno y Trino, además de la Cristología y, claramente, la Escatología.

Desde la introducción del libro, que es subtitulada «La cuestión de la resurrección y la vida futura en el siglo XIV», allí Francisco León Florido recuerda que, generalmente, los desarrollos argumentativos sobre los novísimos solían ser presentados al final de los tratados teológicos y los autores, que serán estudiados cuidadosamente en este libro, siguen esta metodología de exposición que proviene desde el esquema propuesto por Pedro Lombardo en sus Sentencias, 
pero se diferencian de otros pensadores de esta época porque privilegian una «mirada lógicocrítica».

El primer interrogante es por la resurrección general en el futuro, que proviene ciertamente de la experiencia de fe en la resurrección de Cristo a partir de la cual se espera que todos los creyentes participen al final de los días. Esta creencia es formulada en la teología de los primeros siglos del cristianismo siguiendo de manera lógica el dogma cristiano que se encuentra en el corpus paulino y, rápidamente, se ve en la necesidad de acudir a argumentos racionales para no perder credibilidad y poder dar cuenta de la fe en diferentes contextos no cristianos.

De este modo los escolásticos acudieron, por ejemplo, al corpus aristotélico con el fin de dar argumentos fundados en la razón lógica, que permitieran justificar la resurrección tanto como posibilidad metafísica como su viabilidad física, en coherencia con su formulación lógico-gramatical. Así, «Para el aristotélico Tomás de Aquino, el alma, en sentido general, es la forma del cuerpo $y$, siendo el alma intelectual incorpórea y subsistente, el alma humana es incorruptible, a lo que hay que añadir que no estará separada eternamente del cuerpo» ${ }^{1}$.

Por tanto, para Tomás de Aquino la resurrección del alma y el cuerpo es natural en cuanto hace parte de su telos como especie, aunque aquello que realiza la resurrección proviene de la omnipotencia divina. $Y$, aunque existe la posibilidad de prefigurar la vida futura, analógicamente, a partir de la vida y el conocimiento presentes, el conocimiento del alma separada del cuerpo y la visión beatífica requieren de la intervención de Dios, de su iluminación, en cuanto él es acto puro o intelección substancial y lo que sucede en el momento de la visión beatífica de Dios se trata de «una relación cognoscitiva especial (habitudo) del alma hacia la esencia divina, un cara a cara del alma y de la esencia divina ${ }^{2}$, de tal manera

Francisco León Florido y Fernando Rodamilans Ramos, El problema de la resurrección y la vida futura en el siglo XIV (Madrid: Sindéresis, 2016), 13.

2 Francisco León Florido y Fernando Rodamilans Ramos, El problema de la resurrección y la vida futura en el siglo XIV, 15. 
que la resurrección del cuerpo humano no corresponde al mismo hombre numéricamente uno antes de la muerte que después de ella.

Sobre este punto Duns Scoto se interrogaba si en el ser humano la forma substancial dominante es inmaterial, con el fin de buscar argumentos racionales a favor de la resurrección, y un indicio afirmativo sería que el ser humano es capaz de conocimientos superiores, que van más allá de lo sensitivo en alguno de estos sentidos:

No son actos de un órgano corporal; son inmateriales en el sentido de que son puramente formales $y$, por tanto, no son extensos, al modo en que lo es la forma del todo; $\mathrm{y}$, por último, en el sentido de que deben tener un contenido no sensorial, tal como lo experimentamos en el hecho de que formamos conceptos abstractos generales, como el apercibirnos de que conocemos las relaciones: que el animal es el género del hombre, la conciencia de nuestros propios actos por un acto de reflexión, la formación de los primeros principios de la lógica, o la capacidad de razonamiento discursivo ${ }^{3}$.

De cualquier manera, quedaba claro que los actos de conocimiento superiores, inmateriales, se ubican en el ser humano en una parte no orgánica, en el alma intelectiva. Y ya que, si hay algo que ejerza su función sin la materia, también puede existir sin la materia, esta alma intelectiva puede existir sin materia, sin cuerpo. Desde esta misma perspectiva, la razón natural no podrá probar la necesidad de la resurrección pues se trata de una acción sobrenatural y libre que proviene de Dios ${ }^{4}$.

Por su parte, Guillermo de Ockham prefiere dilucidar la inmortalidad del alma mediante la experiencia y no con argumentos racionales, por lo que plantea una serie de dudas sobre la participación del cuerpo en la visión de Dios como recompensa final luego de la muerte y la resurrección como un evento

Francisco León Florido y Fernando Rodamilans Ramos, El problema de la resurrección y la vida futura en el siglo XIV, 19.

Cf. Francisco León Florido y Fernando Rodamilans Ramos, El problema de la resurrección y la vida futura en el siglo XIV, 22. 
sobrenatural, aunque finalmente acepta el pensamiento generalizado en su época. En consonancia con esta visión, Roberto Holcot asume la resurrección como una proposición (promesa) hecha por Jesús y se propone indagar sobre su validez y necesidad, teniendo en cuenta la necesaria confianza del creyente, pero también contemplando la posibilidad del engaño (deceptio Dei) y las consecuencias que se derivan, en primer lugar, respecto a la significación epistemológica de las verdades reveladas ante el conocimiento y la fe; $y$, en segundo lugar, respecto al cuestionamiento sobre la existencia de la contingencia del futuro y la libertad humana de decidir. Esto lleva a una visión de la resurrección sometida a la contingencia, aunque efectivamente suceda como se ha prometido ${ }^{5}$.

La segunda gran problemática expuesta en el libro versa acerca de las consecuencias ante la confianza en el castigo o recompensa luego de la muerte que, según la fe cristiana, es personal y para lo cual, racionalmente, sería necesaria la resurrección del mismo compuesto corpóreo en la misma alma intelectiva. De manera aún más particular, los teólogos medievales que aquí se consideran desarrollan sus ideas respecto a (1) la pervivencia humana en términos de la relación alma y cuerpo, (2) el retorno numérico luego de la interrupción de la existencia (muerte), (3) la imposibilidad de que el compuesto humano se produzca dos veces por causas naturales, (4) el principio según el cual la identidad del todo depende de las partes ${ }^{6}$.

Desde esta perspectiva, Scoto considera que el que resucita es el mismo numéricamente que el que descendió a la muerte, debido a que no hay interrupción en el esse, puesto que las partes siguen como ese. Lo que realmente sucede allí es una mutatio en que se pasa de perder las formas substanciales a recuperarlas y esto gracias a la omnipotencia divina, no a causas naturales, es 
decir, gracias a una intervención milagrosa de Dios ${ }^{7}$.

Por su parte, Ockham comparte varios de los mismos argumentos expuestos por Scoto, pues es lógicamente posible afirmar el resurgimiento o resurrección de la misma cosa numérica, por obra de la voluntad de Dios. Pero entre las diferencias se destaca la hipótesis según la cual lo que resucita no solo es el mismo hombre sino el mismo cuerpo, aunque no lo pueda determinar la razón natural debido a que depende de Dios $^{8}$.

Y la tercera problemática del texto se enfoca hacia el cuestionamiento sobre la recompensa en el cielo que se identifica con la visión beatífica, es decir, con la vida futura en el contexto de la promesa del cristianismo y la búsqueda de la felicidad o perfección humana última, que no puede darse ni en esta vida ni en la etapa de separación del alma y el cuerpo

7 Cf. Francisco León Florido y Fernando Rodamilans Ramos, El problema de la resurrección y la vida futura en el siglo XIV, 30-33.

8 Cf. Francisco León Florido y Fernando Rodamilans Ramos, El problema de la resurrección y la vida futura en el siglo XIV, 34-37. en una unidad inteligible. En este contexto Scoto asume la forma del intelecto bienaventurado como modelo para la ciencia racional, por lo que esta teología es modelo de la metafísica a través de la contemplación intuitiva que considera una distinción en los grados del conocer (natural y sobrenatural) y del ser. Y, del mismo modo, considera que no es necesaria la unión con el cuerpo para, luego de la muerte, tener un acto intelectual perfecto ${ }^{9}$.

Otra perspectiva sobre la vida futura en el cielo se encuentra en Gonzalo Hispano, quien se opone al intelectualismo tomista $y$, en cambio, opta por la superioridad de la voluntad sobre el entendimiento, pues la primera es el fin de la segunda. Consiguientemente, la verdad no puede ser el amor a la sabiduría sino el amor puro hacia Dios desde el corazón y las acciones. Por tanto, el acto del entendimiento es solo una parte de la teología cristiana

Cf. Francisco León Florido y Fernando Rodamilans Ramos, El problema de la resurrección y la vida futura en el siglo $\mathrm{XIV}$, 37-41. 
que pretende acrecentar el amor por el Creador, tarea que no se reduce a los filósofos, sino que se dirige a toda la humanidad. Y, finalmente, a esta compleja temática de la vida futura y la visión beatífica, hay que añadir la polémica que causó la declaración del papa Juan XXII, en el siglo XIV, en cuanto a la visión diferida por parte de las almas de los justos que sucedería antes de la resurrección de los cuerpos, especialmente por las consecuencias para el dogma trinitario y hasta para la devoción a los santos. En este contexto será Guillermo de Ockham, quien había sido perseguido por otra razón distinta (pobreza), el que desate una serie de fuertes críticas sobre las declaraciones papales ${ }^{10}$.

Ciertamente, este libro genera bastantes aportes en cuanto se configura en un texto que contribuye ampliamente a los estudios medievales, pero también en la medida en que las problemáticas

10 Cf. Francisco León Florido y Fernando Rodamilans Ramos, El problema de la resurrección y la vida futura en el siglo XIV, 41-49. aquí presentadas resurgen en cada momento histórico, desde perspectivas bíblicas, sistemáticas o pastorales, con diferentes matices y requieren conocer de primera mano las discusiones que ya se han presentado.

Jaime Laurence Bonilla Morales

\begin{abstract}
Licenciado en Filosofía y Licenciado en Teología por la Universidad de San Buenaventura, sede Bogotá, Especialista en Pedagogía y Docencia Universitaria por la misma institución y Magíster en Filosofía por la Pontificia Universidad Javeriana de Bogotá. Actualmente es estudiante del doctorado en "Artes y humanidades: teología» de la Universidad de Murcia (España). Ha sido coordinador de investigaciones, líder de grupo de investigación y director de posgrados en la Facultad de Teología de la Universidad de San Buenaventura, así como profesor y director de trabajos de grado de la Especialización en Educación Religiosa Escolar. Actualmente es director de la Licenciatura en teología, programa acreditado de alta calidad, así como profesor investigador de la Facultad de Ciencias Humanas y Sociales de esta Universidad, miembro del grupo de investigación Devenir y Editor de la revista Franciscanum (filosofía y teología).Contacto: JBonilla@usbbog.edu. co, laurencebm@yahoo.es.
\end{abstract}

